\title{
Çocuklarla Yapılan Adli Görüşmeler İçin Ulusal Çocuk Sağlığı ve İnsan Gelişim Enstitüsü Protokolü (NICHD) Önerisi: Türkçe Versiyonu
}

\author{
Eda ERMAĞAN-ÇAĞLARa, b, Tuğba TÜRK-KURTÇAc
}

Özet

Adli süreç içerisinde çocuklarla yapılan görüşmelerin uygun bir şekilde yapılması ve olaya dair detaylara gerçeğe en yakın şekilde ulaşılabilmesi hem mağdur olan çocuğa hem de sanığa ilişkin adli sürecin hedeflenen yönde yürütülebilmesini sağlamaktadır. Bu nedenle, özellikle çocuklarla yapılan adli görüşmelerde, çocuktan elde edilecek bilginin nitelik ve niceliğinin sağlanması ve korunması amacıyla gerekli önlemler alınmakta, adli sistem içerisinde ihtiyaç duyulan düzenlemeler yapılmaktadır. Ülkemizde çocuk izlem merkezleri ve adli görüşme odalarının kurulmasının asli nedenlerinden biri de budur. Ancak, söz konusu fiziki düzenlemelerin yanı sıra adli görüşme yöntemlerinin de göz önünde bulundurulması ve adli sistemde çocukla temas içinde olan uzmanların ortak kullanımına sunulan standart bir görüşme protokolünün oluşturulması öncelik arz etmektedir. Bu bağlamda, çocuklarla gerçekleştirilen adli görüşmelerin ve bu görüşmeler için sağlanması gereken kriterlerin önemine değinmek amacıyla yapılan bu çalışmada, özellikle cinsel istismar mağduru çocuklarla gerçekleştirilen adli görüşmelerde çocuklardan daha güvenilir bilgi alabilmek adına oluşturulan Ulusal Çocuk Sağlığı ve İnsan Gelişim Enstitüsü Protokolü'nün (The National Institute of Child Health and Human Development ProtocolNICHD) Türkçe versiyonu tam metin olarak paylaşılmıştır. Aynı zamanda, bu çalışma vasıtasıyla istismar mağduru çocuklarla adli görüşme sürecinde yer alan uzmanlar için yarı yapılandırılmış görüşme prokollerinin kullanımının öneminin vurgulanması amaçlanmıştır.
Anahtar Kelimeler

Çocuk istismarı

Adli görüşme

Görüşme protokolü

NICHD

Makale Hakkında

Geliş Tarihi: 05.11.2018

Kabul Tarihi: 13.03.2020

Doi: $10.18026 /$ cbayarsos.478463

\section{The Proposal of The National Institute of Child Health and Human Development Protocol for Forensic Interviews with Children: The Turkish Version}

\begin{abstract}
Proper forensic interviews with children during the judicial process and accessing the details of the incident as close to the reality as possible ensure that the judicial process concerning both the victim child and the accused can be carried out in the right direction. Therefore, necessary measures are taken within the judicial system in order to ensure and protect the quality and quantity of information to be obtained, especially in judicial interviews conducted with children. This is one of the main reasons for the establishment of child monitoring centers and forensic interview rooms in our country. However, it is a priority to consider the legal arrangements as well as the physical arrangements in question and to establish a standard interview protocol for common use of experts in contact with the child in the judicial system. In this context, the aim of this study was to discuss the importance of forensic interviews with children and the criteria to be met for these interviews, Turkish version of the National Institute of Child Health and Human Development Protocol, which was established in order to obtain more reliable information from children, especially during judicial interviews conducted with children victims of sexual abuse is shared as full text. At the same time, this study aimed to emphasize the importance of the use of semi-structured interview protocols for the experts involved in forensic interviews with child victims of abuse.
\end{abstract}

Keywords

Child abuse

Forensic interview

Interview protocol

NICHD

\begin{tabular}{r} 
About Article \\
\hline Received: 05.11 .2018 \\
Accepted: 13.03 .2020
\end{tabular}

Doi: 10.18026/cbayarsos.478463

a İletişim Yazarı: eda.e.caglar@northampton.ac.uk

bDr. Öğr. Üyesi, University of Northampton, Faculty of Health, Education \& Society, Department of Psychology, Northampton, UK. https://orcid.org/0000-0002-9690-2898

c Dr. Araştırma Görevlisi, Trakya Üniversitesi, Eğitim Fakültesi, Psikolojik Danışmanlık ve Rehberlik Bölümü, Edirne, Türkiye. https://orcid.org/00000002-4361-3769 


\section{Giriş}

Adli süreç içerisinde çocuklarla yapılan adli görüşmelerin uygun bir şekilde yapılması ve olaya dair detaylara gerçeğe en yakın şekilde ulaşılabilmesi hem mağdura hem de sanığa ilişkin adli sürecin hedeflenen yönde yürütülebilmesini sağlamaktadır. Uygun koşul ve yöntemler doğrultusunda gerçekleştirilen bir adli görüşme mağdur olan çocuğun ve aynı zamanda masum bir şüphelinin haklarının korunmasına hizmet edebilmekte (Pipe, Orbach vd., 2008; Pipe, Orbach vd. 2013; Malloy, Katz vd., 2015); adli olaya ilişkin gerçek ve gerçek olmayan detayları ayırt etmeye yardımcı olmakta, adli görüşmenin bir parçası olan kriter bazlı geçerliliği karşılamaktadır (Lamb, Sternberg vd., 1997; Ruby ve Brigham, 1997). Bununla birlikte, yapılan çalışmalar da protokole dayalı görüşmelerin belirtilen gerekliliklere hizmet ettiğini ortaya koymaktadır (Ruby ve Brigham, 1997; Ahern ve Lamb, 2016; Baugerud ve Johnson, 2017).

Özellikle çocuklarla yapılan adli görüşmelerde, çocuktan elde edilecek bilginin nitelik ve niceliğinin sağlanması ve korunması adli sürecin sağlıklı yürütülebilmesi açısından ayrıca önem taşımaktadır (Baugerud ve Johnson, 2017). Çocuklarla gerçekleştirilmesi hedeflenen sağlıklı bir adli görüşme sürecinden olaya ilişkin asli detaylara ulaşılabilmesi için serbest anlatıyı teşvik edecek açık uçlu soruların sorulması (Sternberg, Lamb vd, 2001; ErmağanÇağlar ve Kocabaşoğlu, 2018), alternatif açıklamaları ortaya çıkaracak hipotezlerin test edilmesi, çocuğu etkileyebilecek kültürel ve gelişimsel faktörlerin göz önünde bulundurulması beklenmektedir. Görüşmecinin ön yargıları ve beklentilerinin çocuğun olay hafızası ve ifadeleri üzerindeki etkilerinin (Rohrabaugh, London ve Hall, 2006) dikkate alınması ve görüşme sırasında çocuğa verilen geri bildirimlerin onaylayıcı ve ön yargılardan bağımsız olması sağlanmalıdır. Benzer şekilde, alınan ifadelerin güvenirliğini arttırmak amacıyla ifade alımı sırasında çocuğa "bilmiyorum" cevabını kullanma hakkının verilmesi ve görüşme öncesinde bu bilginin çocukla paylaşılması önemli bir unsur olarak karşımıza çıkmaktadır (Ermağan, 2015). Bu nedenler doğrultusunda, alana ilişkin yapılan çalışmalar neticesinde, söz konusu görüşme koşullarının sağlanabilmesi için adli görüşmelerde kullanılmak üzere standart görüşme protokollerinin oluşturulması hedeflenmiştir. Michigan Forensic Interview Protocol, The ASPAC Guidelines, Memorandum of Good Practice, The CornerHouse Forensic Interview Protocol ve The National Institute of Child Health and Human Development Protocol (NICHD Protocol) bu protokoller arasında en çok tercih edilenlerdir. Buna karşılık, uygulama sonuçlarını elde edebilmek ve protokolün farklı ülke ve kültürlere olan uygunluğunu saptayabilmek amacıyla yapılan araştırmalar neticesinde NICHD protokolünün literatürde belirtilen kriterleri karşıladığı sonucuna varılmıştır.

NICHD protokolü adım adım detaylı bir görüşme sürecinin nasıl olması gerektiği ile ilgili bir çerçeve sağlayarak, hafızadan geri çağırmayı ve iletişimi kolaylaştırmaktadır (Benia, HauckFilho ve Dillenburg \& Stein, 2015). Açı uçlu ve davet tipi soruların etkili bir şekilde kullanılması ile çocuğun geri çă̆ırma hafızasına daha fazla odaklanmakta, böylece daha kesin bilgilerin elde edilmesi sağlanmaktadır (Pipe, Orbach vd., 2008). Ayrıca, görüşme sürecinde çocuğun rahat olabilmesinin önemli bir etken olduğunu göz önünde bulundurarak görüşme başlangıcında gündelik olaylara ve hobilere yer vermekte; görüşmeciyle çocuk arasındaki iletişim ve güven ortamının kurulmasına (Price, Ahern ve Lamb, 2016); duygulara yönelik ifadelere yer vermesiyle çocuğun tanıklığının zenginleştirilmesine (Karni-Visel, Hershkowitz v., 2019) imkân sağlamaktadır. 
Alan yazındaki diğer çalışmalar incelendiğinde ise, söz konusu protokolün hem standart görüşmelerle hem de Memorandum of Good Practice (MoGP) ile karşılaştırıldığı görülmüştür. Standart görüşmeler ile karşılaştırıldığında NICHD protokolünün daha fazla davet ediciler, daha az seçenekli sorular ve önericiler kullanıldığı; böylece çocuktan daha fazla bilgi elde edilebildiği saptanmıştır (Benia, Hauck-Filho vd., 2015). NICHD protokolüne dayalı olarak yapılan görüşmelerde, standart görüşmelere göre daha fazla ayrıntı elde edildiği sonucuna varılmıştır (Orbach, Hershkowitz vd., 2000). Memorandum of Good Practice (MoGP) ile karşılaştırılan çalışmalarda ise NICHD protokolü ile daha fazla serbest hatırlama davetlerini, daha az yönlendirici, seçenekli ve önerici sorular kullanıldığı ve böylece adli olaya ilişkin daha fazla bilgi elde etmeyi sağladığı görülmüştür (Lamb, Orbach vd., 2009). NICHD protokolü ile yürütülen görüşmelerde MoGP ile yapılan görüşmelere göre çocukların görüşmeciden gelen destekleyici tepkiler karşısında olaya ilişkin bilgi verme ve görüşmeciye açılma hususlarında daha işbirlikçi oldukları dikkat çekmiştir (Ahern ve Lamb, 2016),

Çocuklarla gerçekleştirilen adli görüşmelerin ve bu görüşmeler için sağlanması gereken kriterlerin önemine değinmek amacıyla yapılan bu çalışmada, özellikle cinsel istismar mağduru çocuklarla gerçekleştirilen adli görüşmelerde çocuklardan daha güvenilir bilgi alabilmek adına oluşturulan ve yapılan birçok ampirik ve saha çalışması neticesinde örnek bir model olarak sunulan Ulusal Çocuk Sağlığı ve İnsan Gelişim Enstitüsü Protokolü'nün (NICHD) Türkçe versiyonu tam metin olarak paylaşılmıştır. Aynı zamanda, bu çalışma vasıtasıyla istismar mağduru çocuklarla adli görüşme sürecinde yer alan uzmanlar için yarı yapılandırılmış görüşme prokollerinin kullanımının önemine dikkat çekilmesi amaçlanmıştır.

\section{Ulusal Çocuk Sağlığı ve İnsan Gelişim Enstitüsü Protokolü (NICHD)}

Ulusal Çocuk Sağlığı ve İnsan Gelişimi Enstitüsü Protokolü hafızadan geri çağırma ve iletişim teknikleri dizilerini içeren kanıta dayalı bir görüşme protokolüdür (La Rooy, Brubacher vd., 2015). Protokol yarı yapılandırılmış bir görüşme formuna sahiptir ve adli görüşme sürecinde çocuğu yönlendirmeden görüşmeciye adım adım rehberlik ederek görüşmenin detaylandırılmasını sağlamaktadır (Benia, Hauck-Filho vd., 2015).

Çocuklarla gerçekleştirilen adli görüşme süreçlerini işlevsel bir şekilde yürütebilmek adına başta Kanada, Finlandiya, İskoçya, İsrail, Japonya, Kore, Norveç, Portekiz ve Amerika Birleşik Devletleri olmak üzere birçok ülkede aktif bir şekilde kullanılan NICHD protokolünün bütün aşamalarında serbest anlatımın ön plana alındığ görülmektedir. Söz konusu bu özellik protokolün kuvvetli yönlerinden biri olarak ele alınmaktadır. Bununla birlikte, istismar mağduru çocuklarla yapılan protokole dayalı görüşmeler ve standart görüşmeler karşılaştırıldığında protokole dayalı görüşmelerde daha fazla açık uçlu soru ve daha az seçenekli soru kullanıldığı dikkat çekmiştir (Sternberg, Lamb vd., 2001). Öyle ki bu oran açık uçlu soru sorma açısından protokole dayalı görüşmelerde $\% 89$, standart görüşmelerde ise $\% 36$ olarak saptanmıştır (Sternberg, Lamb vd., 2001). Protokoldeki amaç serbest anlatı sorularından gelen bilgileri maksimize etmeye çalışmaktır. Ayrıca, serbest anlatı sorularının kullanımı çocuktan alınan bilgilerin güvenilirlik oranını da arttırmaktadır (Benia, Hauck-Filho vd., 2015). Yapılan bir diğer çalışmada, söz konusu protokole dayalı görüşmelerde mağdur çocuklardan elde edilen bilgilerin \%60'ından fazlasının daha güvenilir olan açık uçlu sorularla elde edildiği tespit edilmiştir (Sternberg, Lamb vd., 2001). Buna ek olarak, görüşmecilerin neredeyse tamamının çocukla doğru-yalan farkı hakkında konuştuğu, neredeyse yarısının çocuğun bilmiyorum demesine izin verdiğini, yine görüşmecilerin büyük bir kısmının görüşmeyi bitirirken teşekkür ettiğini, yarısından daha azının çocuğa sorusu olup olmadığını 
sorduğunu ve davanın gelecek adımlarını anlattığını görmüşlerdir (Sternberg, Lamb vd., 2001). Çocukla kurulan iletişimin önemini göz önünde bulunduran protokoldeki asli amaçlardan biri de çocuğun kendini baskı altında hissetmesine engel olmaktır. Özellikle görüşmenin başında çocuğun 'bilmiyorum' deme hakkının olduğunun belirtilmesi, çocuğu görüşmeci tarafından sorulan sorular karşısında gerçekçi olmayan cevaplar vermesinden alıkoymaktadır ki bu da görüşmenin güvenilirliğini arttıran etkenlerden biri olmaktadır (Ermağan, 2015).

Ahern ve Lamb (2016), cinsel istismar kurbanı olduklarını belirten 4-13 yaş grubundaki çocukların adli görüşmelerindeki görüşmecinin tepkilerini incelediği çalışmalarında, görüşmelerin yarısını çocuğun istismara ilişkin ilk bildirimine odaklanan açıklama aşamasını içeren NICHD protokolü ile, diğer yarısını ise çocuğun ilk açılımının sorgulanmasını içermekle birlikte planlanan bir açılma aşamasının olmadığı Memorandum of Good Practice (MoGP) protokolü ile yapmışlardır. Çalışma sonunda, cinsel istismar mağduru olan çocukların görüşmeciye cevap verdikleri anlar noktasında destekleyici ve destekleyici olmayan çeşitli tepkiler bildirmişlerdir. Destekleyici olmayan tepkiler çocukların daha endişeli, suçlu veya öfkeli hissetmesine ve bilgi verirken daha huzursuz olmalarına neden olduğu görülmüştür (Ahern ve Lamb, 2016). Ancak, NICHD protokolü ile yürütülen görüşmelerde çocukların görüşmeciden gelen destekleyici tepkiler karşısında olaya ilişkin bilgi verme ve görüşmeciye açılma hususlarında daha işbirlikçi oldukları dikkat çekmiştir. Bu doğrultuda, NICHD protokolünün kullanımının, görüşmecinin tepkileri karşısında istismara maruz kalan çocuğun görüşmeden vazgeçme olasılığını ortadan kaldırabildiğini söylemek mümkün olmaktadır.

NICHD protokolü açık uçlu sorular kullanarak hem daha küçük yaşlardaki hem de daha büyük yaşlardaki çocukların bildirimlerini arttırmada da etkilidir. Söz konusu protokol, çoğunlukla açı uçlu soruların tercih edilmesi ve daha az yönlendirici, öneri ifadeli sorulara yer verilmesi sayesinde olaya dair daha fazla detayın ortaya çıkarılmasını sağlamaktadır (Pipe, Orbach vd., 2008). Bu durum görüşmeci tarafından yapılan yönlendirmelerin neden olabileceği çocuk görgü tanığının olay belleğinden uzaklaşmasını da engellemekte (ErmağanÇağlar ve Kocabaşoğlu, 2018) ve sadece çocuğun ifade ettiği bilgiler doğrultusunda olaya odaklanılmasını desteklemektedir.

Ayrıca, NICHD protokolünün takip edildiği görüşmelerde ilişki kurma aşamasında çocuk tarafından istismarla ilişkisi olmayan olayların serbestçe anlatıldığı nötr olay ve hobiler hakkında soruların da yer bulduğu görülmektedir. Bu aşama, özellikle daha büyük yaştaki çocuklarda çocuğun üretkenliğini ve olası rahatlı̆̆ını arttırırken suç dışı diğer olaylar ve hobiler aracılığıyla hedef olaya ilişkin daha uzun cevaplar almayı da sağlamaktadır (Price, Ahern ve Lamb, 2016). Bunun beraberinde, görüşmenin başında çocuğun neden görüşme ortamında olduğu ve görüşmenin yapılma amacı net bir şekilde ifade edildiği için hobiler ya da diğer yaşam olaylarına yönelik kurulan sohbetin çocuğun görüşmenin amacından uzaklaşmasına sebebiyet vermediği gözlenmektedir.

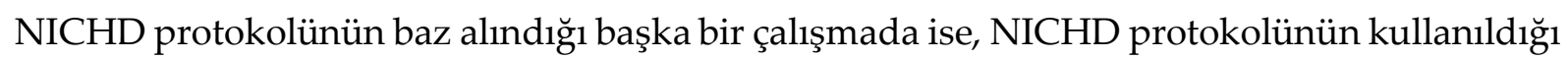
55 adli görüşme kaydı ile protokol güdümlü olmayan 50 adli görüşme kaydı karşılaştırılmıştır (Orbach, Hershkowitz vd., 2000). Çalışmada aynı deneyime sahip 6 görüşmeci tarafından yürütülen adli görüşmeler dikkate alınmıştır. Araştırma sonucunda NICHD protokolüne bağlı kalınarak yapılan görüşmelerde çocukların yaşadıkları cinsel istismara yönelik daha ayrıntılı bilgilere ulaşılabildiği saptanmıştır (Orbach, Hershkowitz vd., 2000). 
NICHD protokolü davet tipi soruları önererek çocuğun geri çağırma hafızasına daha fazla odaklanmakta ve böylece olaya ilişkin bilgilerin daha net bir şekilde görüşmede yer almasına olanak sağlamaktadır.

\section{Sonuç}

Çocuklarla yapılan adli görüşmelerin sağlıklı bir şekilde yürütülmesi hem çocuğun iyilik halinin korunabilmesi hem de adli sürecin işlevsel bir şekilde devam ettirilmesi açısından önem kazanmaktadır. Bu nedenle, birçok ülkede çocuklarla yapılan adli görüşmelerin daha sağlıklı yürütülebilmesi için Çocuk Koruma Merkezleri, Corner House ve Barnahaus ve benzeri merkezler kurulmuştur. Öte yandan bu merkezlerin kurulmasıla birlikte adli görüşmelerin güvenirliğini sağlamak amaciyla Michigan Forensic Interview Protocol, The ASPAC Guidelines, Memorandum of Good Practice, The CornerHouse Forensic Interview Protocol ve The NICHD Protocol şeklinde standartlaştırılmış görüşme kılavuzları oluşturulmuştur. Ülkemizde ise söz konusu standartların sağlanabilmesi için Adli Tıp Kurumu, ünicersitelere bağlı Çocuk Koruma Merkezleri ve Çocuk İzlem Merkezleri, Adli Görüşme Odalarının kurulumu sağlanmıştır. Belirtilen kurumlarda ihtiyaç duyulan donanımların ve uzman eğitimlerinin sağlanmasında gerekli hassasiyetler gösterilmiş, çalışmalar yürütülmüştür. Ancak, yapılan çalışmalar neticesinde hem kurum içi hem de diğer ilgili kurumlarla olması gereken bilgi paylaşımını destekleyecek görüşme protokollerinin ve standartlarının oluşturulamadığı görülmüştür (Türk, 2017).

Çocuklarla yapılan adli görüşme süreçlerine ilişkin yapılan çalışmalar, uygulama açısından uzmanlar arasında görülen farklılıkların adli görüşme ve değerlendirme sürecinde önemli noktaların gözden kaçmasına ve bu nedenle tekrar görüşmelerine ihtiyaç duyulmasına sebebiyet verdiğini ortaya koymaktadır. Ayrıca, söz konusu duruma bağlı olarak sürecin çocuk için yıpratıcı olması; yapılan tekrar görüşmelerine bağlı olarak çocuğun olay hafızasında istemsiz değişikliklerin meydana gelmesi ve zamanla olayın gerçekliğinden uzaklaşması da uygulamalar arasındaki farklılığın getirmekte olduğu riskler arasındadır. Belirtilen risklerin ortadan kaldırılmasındaki en önemli nokta ise alanda çalışan uzmanlar tarafından tek bir protokolün kullanılmasıdır.

Görüşmelerin standart bir protokol kılavuzluğunda gerçekleştirilmesi ise hem çocukla yapılan adli görüşmelerdeki standardizasyonu sağlamakta hem de adli sürecin bir sonraki evresinde tespit edilmesi olası eksik bilgilerin giderilmesinde uzmana rehberlik etmektedir. Ayrıca, standart bir protokolün takibi görüşmenin nasıl yürütüleceği hususunda uzmana güven vermekte ve görüşmenin üzerinde yaratacağı yetkinlik stresinden de büyük ölçüde kurtulmasını sağlayarak bunu çocuğa yansıtmasına engel olmaktadır. Bununla birlikte, çocukla yapılan adli görüşmelerde bir standardın sağlanması ve görüşmelerin ortak yaklaşımla yarı yapılandırılmış bir protokol vasıtasıyla yürütülmesi alınan ifadelerin güvenilirliğini arttırırken çocuğun yararının da göz önünde bulundurulmasına olanak sağlamakta, uzmanlar için bir yol haritası olmaktadır. Adli olaya ilişkin temas içinde olan diğer birimlerle (polis, hastane vb.) yapılması gereken bilgi alışverişini daha sistemli hale getirmekte ve sistemli bir olay kaydının ortaya çıkmasına imkân sağlamaktadır.

$\mathrm{Bu}$ sebeplerden ötürü, söz konusu çalışmayla, farklı ülke ve kültürler kapsamında yaygın olarak kullanılan ve etkililiği çeşitli araştırmalarla kanıtlanmış olan NICHD protokolüne ait temel özelliklerin ve bu özelliklerin adli görüşmenin verimliliği açısından öneminin ele alınması; protokolün Türkçe çevirisinin uzmanların kullanımı için paylaşılması 
amaçlanmıştır. $\mathrm{Bu}$ amaç çerçevesinde protokolün uygulamalarına ilişkin araştırma sonuçlarına yer verilmiş; protokolün farklı kültürler için de geçerlilik arz ettiği sonucuna varılmıştır. Ancak belirtilenlerin yanı sıra, NICHD protokolünün uygulamaları için ülkemiz sistemine uygun birtakım düzenlemelerin yapılabileceği öngörülmektedir. Türk Ceza Kanuna bağlı olarak suçun niteliğini anlamayı sağlayacak soruların protokole eklenmesi önerilen düzenlemelerden ilkidir. Bununla birlikte, görüşmecinin cinsiyetinin görüşme sürecini etkilediği sonucundan yola çıkarak (Türk, 2017) istismar mağduru çocuğa görüşmeciyi seçme hakkının verilmesinin diğer bir önemli husus olduğu öngörülmektedir.

Sonuç olarak, bu çalışma sadece Ulusal Çocuk Sağlı̆̆ı ve İnsan Gelişim Enstitüsü Protokolü (The National Institute of Child Health and Human Development (NICHD) Protocol) protokolü ile sınırlı olmakla birlikte uluslararası alanda kullanılan diğer protokoller ve Türkiye' deki adli görüşme teknikleri incelenerek çalışmada yer verilen öneriler çerçevesinde Türk adalet sistemine, sosyal ve kültürel özelliklerine uygun bir adli görüşme protokolünün geliştirilmesinin de önemli olduğu düşünülmektedir.

\section{Teşekkür}

Bu çalışmada Ulusal Çocuk Sağlığı ve İnsan Gelişim Enstitüsü Protokolü'nün yayınlanmasına destek verdiği için Dr. David La Rooy'a teşekkür ederiz.

\section{Kaynakça}

Ahern, E.C. \& Lamb, M.E. (2016). Children's reports of disclosure recipient reactions in Forensic interviews: Comparing the NICHD and MoGP protocols. Journal of Police and Criminal Psychology, 32( 2), 85-93. doi:10.1007/s11896-016-9205-x

Baugerud, G.A. \& Johnson, M.S. (2017). The NICHD Protocol: Guide to Follow Recommended Investigative Interview Practices at the Barnahus? Collaborating Against Child Abuse. In: Johansson S., Stefansen K., Bakketeig E., Kaldal A. (eds) Collaborating Against Child Abuse (pp.121-143). Palgrave Macmillan, Cham.

Benia, L. R., Hauck-Filho, N., Dillenburg, M. \& Stein, L.M.(2015). The NICHD investigative interview protocol: A meta-analytic review. Journal of Child Sexual Abuse, 24( 3), 259-279. doi: 10.1080/10538712.2015.1006749

Ermağan, E. (2015). Çocuk görgü tanıklı̆̆ının güvenilirliğinin incelenmesi. (Doktora Tezi, İstanbul Üniversitesi, İstanbul). Erişim Adresi: https://tez.yok.gov.tr/

Ermağan-Çağlar, E. \& Kocabaşoğlu, N. (2018). Bellek boşluklarını doldurmaya zorlamanın çocuk görgü tanığı belleği üzerindeki olumsuz etkileri. Türkiye Adalet Akademisi Dergisi, 9 (34), 451-473.

Karni-Visel, Hershkowitz, Y.I, Lamb, M.E. \& Blasbalg, U. (2019). Facilitating the Expression of Emotions by Alleged Victims of Child Abuse During Investigative Interviews Using the Revised NICHD Protocol. Child Maltreatment, 24 (3), 310-318. doi:10.1177/1077559519831382

La Rooy, D., Brubacher, S.P., Aromaki-Stratos, A., Cyr, M., Hershkowitz, I., Korkman, J., Myklebust, T., Nakka, M., Peixoto, C.E., Roberts, K.P., Stewart, H. \& Lamb, M.E. (2015). The NICHD protocol: A review of an internationally-used evidence-based tool for training child forensic interviewers. Journal of Criminological Research, Policy and Practice, 2(1), 76-89. 
Lamb, M.E., Orbach, Y., Sternberg, K.J., Aldridge, J., Pearson, S., Stewart, H.L., Esplin, P.W. \& Bowler, L. (2009). Use of a structured investigative protocol enhances the quality of investigative interviews with alleged victims of child sexual abuse in Britain. Applied Cognitive Psychology, 23(4), 449-467.

Lamb, M.E., Sternberg, K.J., Esplin, P.W., Hershkowitz, I., Orbach, Y. \& Hovav, M. (1997). Criteria-Based Content Analysis: A field validation study. Child Abuse and Neglect, 21(3), 255-264.

Lamb, M.E., Sternberg, K.J., Orbach, Y., Esplin, P.W., Stewart, H. \& Mitchell, S. (2003). Age differences in young children's responses to open-ended invitations in the course of forensic interviews. Journal of Consulting and Clinical Psychology, 71(5), 926-934.

Malloy, L.C., Katz, C., Lamb, M.E. \& Mugno, A.P. (2015). Children's requests for clarification in investigative interviews about suspected sexual abuse. Applied Cognitive Psychology, 29(3), 323-333. doi: 10.1002/acp.3101.

Orbach, Y., Hershkowitz, I., Lamb, M.E., Sternberg, K.J., Esplin, P.W. \& Horowitz, D. (2000). Assessing the value of structured protocols for forensic interviews of alleged child abuse victims. Child Abuse \& Neglect, 24(6), 733-752.

Pipe, M.E., Orbach, Y., Lamb, M.E., Abbott, C.B. \& Stewart, H. (2008). Do best practice interviews with child abuse victims influence case processing. (Unpublished report) US Department of Justice. ISO 690.

Pipe, M.E., Orbach, Y., Lamb, M.E., Abbott, C.B. \& Stewart, H. (2013). Do case outcomes change when investigative interviewing practices change? Psychology, Public Policy, and Law, 19 (2), 179-190.

Price, E.A., Ahern, E.C. \& Lamb, M.E. (2016). Rapport-building in investigative Interviews of alleged child sexual abuse victims. Applied Cognitive Psychology, 30(5), 743-749. doi: 10.1002/acp.3249.

Rohrabaugh, M., London, K. \& Hall, A.K. (2016). Planning the forensic interview. In W.T. O'Donohue \& M. Fanettı (Eds.) Forensic interviews regarding child sexual abuse: A guide to evidence-based practice (pp. 197-218). Switzerland: Springer International Publishing.

Ruby, C.L. \& Brigham, J.C. (1997). The usefulness of the criteria-based content analysis technique in distinguishing between truthful and fabricated allegations: A critical review. Psychology, Public Policy, and Law, 3(4), 705-737. doi:10.1037/1076-8971.3.4.705

State Of Michigan Governor's Task Force On Child Abuse And Neglect And Department Of Human Services. (2011). Forensic interview protocol. (3rd edition). https://www.michigan.gov/documents/dhs/DHS-PUB-0779 211637 7.pdf • (3 Eylül 2018 tarihinde indirilmiştir.)

Sternberg, K.J., Lamb, M.E., Davles, G.M. \& Westcott, H.L. (2001). The memorandum of good practice: Theory versus application. Child Abuse \& Neglect, 25(5), 669-681.

Sternberg, K.J., Lamb, M.E., Orbach, Y., Esplin, P.W. \& Mitchell, S. (2001). Use of a structured investigative protocol enhances young children's responses to free-recall prompts in the course of forensic interviews. Journal of Applied Psychology, 86(5), 997-1005. 
Çocuklarla Yapılan Adli Görüşmeler İçin Ulusal Çocuk Sağlığı ve İnsan Gelişim Enstitüsü Protokolü (NICHD) Önerisi: Türkçe Versiyonu

The Institute for Human Services (2010). 203: Investigative Interviewing in Child Sexual Abuse Cases Standard Curriculum. University of Pittsburgh, School of Social Work, Pittsburgh.

Türk, T. (2017). Cinsel istismar mağduru çocuk ile yapılan adli görüşmelerin adli görüşme teknikleri açısından incelenmesi. (Yüksek Lisans Tezi, İstanbul Üniversitesi, İstanbul). Erişim Adresi: https://tez.yok.gov.tr/

\section{Ulusal Çocuk Sağlığı ve İnsan Gelişim Enstitüsü (NICHD) Protokolü: Görüşme}

\section{Rehberi}

\section{Giriş}

1. “Merhaba, benim adım

ve ben bir polis memuruyum. (Odada yer alan başka biri varsa onları da tanıtın. Ancak ideal olarak başka birilerinin odada olmaması önerilmektedir.) Bugün ve şu an saat

"Gördüğün üzere burada bir kameramız ve bir mikrofonumuz var. Bunlar konuşmalarımızı kaydedecek ve bu sayede anlattıklarını hatırlayabileceğim. Bazen bazı şeyleri unutabilirim ve bu kayıt cihazları her şeyi yazmak zorunda kalmadan seni dinlememi sağlıyor."

“Görevlerimden biri yaşadıkları olaylar hakkında çocuklarla (gençlerle) konuşmak. Birçok çocukla (gençle) görüşme yapıyorum, böylece yaşamış oldukları gerçek olayları bana anlatabiliyorlar. Bu nedenle, başlamadan önce, gerçekleri anlatmanın ne kadar önemli olduğunu anladığından emin olmak istiyorum." (Küçük yaş grubundaki çocuklar için "doğru" nedir? Doğru olmayan nedir? açılayın.)

“Benim ayakkabılarım kırmızı (ya da yeşil) dersem, bu doğru mudur değil midir?

(Bir cevap vermesi için bekleyin, sonra şöyle söyleyin:)

1. "Bu doğru değil, çünkü benim ayakkabılarımın gerçek rengi (siyah/mavi vb.). Eğer ben şu an oturduğumu söylersem, bu doğru mudur, doğru değil midir?"

(Bir cevap vermesi için bekleyin.)

2. "Bu doğruydu/yanlıştı, çünkü gördüğün üzere ben şu an oturuyorum."

“Doğruyu söylemenin ne demek olduğunu anladığını görüyorum. Bugün bana sadece doğru olanları anlatman çok önemli. Bana, sadece başına gelen şeyleri (yaşadıklarını) anlatmalısin."

(Bekleyin.)

3. "Görüşme sürecinde, eğer sana sorduğum soruyu anlamazsan bana "Anlamadım" de. Tamam mi?"

(Bekleyin.)

"Eğer söylediğin şeyi/anlattığını anlamazsam, senden yeniden açıklamanı isteyeceğim." (Bekleyin.)

4. "Eğer sana bir soru sorarsam ve sen cevabını bilmiyorsan bana "Bilmiyorum" de." 
“Örneğin, sana köpeğimin adı nedir (veya oğlumun adı nedir?) diye sorarsam ne söylerdin?"

(Bir cevap vermesi için bekleyin.)

(Eğer çocuk “Bilmiyorum” derse, ona şöyle söyleyin:)

5. “Doğru. Bilmiyorsun, değil mi?"

(Ĕ̆er çocuk bir tahminde bulunmaya çalışırsa, ona şöyle söyleyin:)

“Hayır, bilmiyorsun çünkü beni tanımıyorsun. Cevabı bilmediğin zaman, tahmin etmeye çalışma, sadece bilmediğini söyle."

(Bekleyin.)

6. “Ve, eğer yanlış olan (doğru olmayan) birşeyler söylersem, bana söylemelisin. Tamam mi?"

(Bir cevap vermesi için bekleyin.)

7. “Örneğin, eğer 2 yaşında bir kız çocuğu (görüşme yaptığınız çocuğun 5 yaşında bir erkek çocuğu olduğunu düşünelim), olduğunu söylersem ne söylerdin?"

(Eğer çocuk kabul etmez ve doğru olmadığını söylerse, şöyle söyleyin:)

“Eğer yanlış birşey söylersem ve sana 2 yaşında bir kız çocuğu (görüşme yaptığınız çocuğun 5 yaşında bir erkek çocuğu olduğunu düşünelim) olduğunu söylersem ne söylerdin?"

(Bir cevap vermesi için bekleyin.)

8. “Evet bu doğru. Yanlış birşey söylersem veya bir hata yaparsam bana ne söylemen gerektiğini şimdi biliyorsun."

(Bekleyin.)

9. “Örneğin, senin oturuyor olduğunu söyleseydim ne söylerdin?”

(Bir cevap vermesi için bekleyin.)

"Tamam."

İlişkinin Kurulması

"Şimdi, seni daha iyi tanımak istiyorum."

1. “Bana yapmaktan hoşlandığın şeyleri anlat."

(Cevap vermesi için çocuğu bekleyin.)

(Eğer çocuk açıkça detaylı bir cevap verirse, 3. soruya geçin.)

(Eğer çocuk cevap vermezse, kısa bir cevap verirse veya ne yapacağını bilemezse, şöyle sorabilirsiniz:)

2. "Gerçekten, seni daha iyi tanımak istiyorum. Yapmaktan hoşlandığın şeyleri bana anlatmana ihtiyacim var."

(Bir cevap vermesi için bekleyin.)

3. "Daha fazla bilgi verir misin?" (Çocuğun bahsettiği etkinlik/aktiviteye yönelik olarak sorulur. Ancak televizyon, video oyunları ya da hayali aktivitelere odaklanmaktan kaçının.) 
(Bir cevap vermesini bekleyin.)

\section{Olay Hafızasının Üzerinde Çalışılması}

\section{Özel Bir Günün Belirlenmesi}

(Not: Bu bölüm olayın içeriğine bağlı olarak değişebilir.)

(Görüşme öncesinde çocuğun yaşadığı bir olay (etkinlik) (okulun ilk günü, doğum günü partisi, tatil gibi) belirleyin ve belirtilen soruları bu olay (etkinlik) üzerinden sorun. Ĕger mümkünse, iddia edilen veya şüphe edilen istismar olayıyla aynı zamanda gerçekleşen bir olay ya da etkinlik seçin. Eğer istismar olayı belirgin bir gün ya da olay sırasında gerçekleşmişse, soruları farklı bir olay üzerinden sorun.)

"Senin hakkında, yaptığın şeyler hakkında daha çok şey bilmek istiyorum."

1. “Birkaç gün (hafta) önce okulun ilk günüydü (tatildi, doğum günündü vb.). Bana o gün yaşananları anlatır mısın?"

(Bir cevap vermesi için bekleyin.)

1.1. “O günü (etkinliği, partiyi vb.) iyi düşün ve sabah uyandığın zamandan (çocuğun bir önceki soruya verdiği cevapta bahsettiği an/etkinliğin bir bölümü) ... zamana kadar neler olduğunu bana anlat."

(Bir cevap vermesi için bekleyin.)

(Not: Bu soruyu bu bölüm süresince ihtiyaç duyduğunuz kadar kullanabilirsiniz.)

\section{2. "Peki sonra ne oldu?}

(Bir cevap vermesi için bekleyin.)

(Not: Bu soruyu bu bölüm süresince ihtiyaç duyduğunuz kadar kullanabilirsiniz.)

1.3. “(Çocuğun bir önceki soruya verdiği cevapta bahsettiği an)dan sonra gece yatağa gidinceye kadar geçen zamanda neler olduğunu bana anlat."

(Bir cevap vermesi için bekleyin.)

(Not: Bu soruyu bu bölüm süresince ihtiyaç duyduğunuz kadar kullanabilirsiniz.)

1.4. (Çocuğun bahsettiği olaya ilişkin olarak) “Daha fazla anlatır mısın?”

(Bir cevap vermesi için bekleyin.)

(Not: Bu soruyu bu bölüm süresince ihtiyaç duyduğunuz kadar kullanabilirsiniz.)

\section{5. “Bundan daha önce bahsetmiştin. Bana daha fazla şey anlatır mısın?"}

(Bir cevap vermesi için bekleyin.)

(Not: Bu soruyu bu bölüm süresince ihtiyaç duyduğunuz kadar kullanabilirsiniz.)

(Eğer çocuk olay hakkında basit bir açılama yaparsa, 2-2.5. numaralı sorulardan devam ediniz.)

(Not: Eğer çocuk olay hakkında detaylı bir açılama yaparsa, şöyle söyleyin:)

"Sana olanlarla ilgili olarak hatırladıklarını bana anlatman çok önemli. İyi ya da kötü olan herşeyi bana anlatabilirsin." 


\section{Dün}

2. "Sana olanlarla ilgili hatırladığın herşeyi bilmek istiyorum. Dün yataktan kalktıktan sonraki zamandan gece uyuyuncaya kadar geçen zamanda olanları bana anlat."

(Bir cevap vermesi için bekleyin.)

2.1. “Hiç birşeyi atlamanı istemiyorum. Sabah yataktan kalktığın andan (çocuğun bir önceki soruya verdiği cevapta bahsettiği an)a kadar olanları bana anlat."

(Bir cevap vermesi için bekleyin.)

\section{2."Sonra neler oldu?"}

(Bir cevap vermesi için bekleyin.)

(Not: Bu soruyu bu bölüm süresince ihtiyaç duyduğunuz kadar kullanabilirsiniz.)

2.3.“(Çocuğun bir önceki soruya verdiği cevapta bahsettiği an)dan sonra gece yatağa gidinceye kadar geçen zamanda neler olduğunu bana anlat."

(Bir cevap vermesi için bekleyin.)

2.4. (Çocuğun bahsettiği olaya ilişkin olarak) “Daha fazla anlatır mısın?"

(Bir cevap vermesi için bekleyin.)

(Not: Bu soruyu bu bölüm süresince ihtiyaç duyduğunuz kadar kullanabilirsiniz.)

\section{5. "Bundan daha önce bahsetmiştin. Bana daha fazla şey anlatır mısın?"}

(Bir cevap vermesi için bekleyin.)

(Not: Bu soruyu bu bölüm süresince ihtiyaç duyduğunuz kadar kullanabilirsiniz.)

\section{Bugün}

Eğer çocuk düne ilişkin yeterli derecede detaylı cevap vermiyorsa, bugüne ilişkin 2' den 2.5.'e olan soruları tekrarlayınız. Ancak, bu defa referans alınan zamanı "buraya geldiğin zaman" şeklinde değiştirin.

"Sana gerçekten olan şeyler hakkında hatırladığın herşeyi bana anlatman çok önemli."

\section{Görüşmenin Temel Bölümü}

\section{Temel Konulara Geçiş}

"Şimdi seni daha iyi tanıdığıma göre bugün neden burada olduğun hakkında konuşmak istiyorum."

(Eğer çocuk cevap vermeye başlarsa bekleyin.)

(Eğer çocuk iddia edilen olay hakkında kısa bir cevap verirse ("Babam bana vurdu." veya "Ahmet benim penisime dokundu." gibi) 10. sorudan devam edin.)

(Eğer çocuk olay hakkında detaylı bir cevap verirse, 10.1. sorudan devam edin.)

(Eğer çocuk herhangi bir suçlamada bulunmazsa, 1. sorudan devam edin.)

1. “Sana birşeyler olmuş olabileceğini anlıyorum. Başından sonuna kadar olan herşeyi bana anlat."

(Bir cevap vermesi için bekleyin.) 
(Eğer çocuk suçlamada bulunursa, 10. sorudan devam edin.)

(Eğer çocuk olay hakkında detaylı bir cevap verirse, 10.1. sorudan devam edin.)

(Eğer çocuk herhangi bir suçlamada bulunmazsa, 2. sorudan devam edin.)

2. "Sana söylediğim gibi benim işim başına gelen şeyler hakkında çocuklarla konuşmak. Neden burada olduğunu (buraya geldiğini/benim burada olduğumu) bana anlatman çok önemli. Annenin (babanın, dedenin, büyük annenin vb.) seni neden bugün buraya getirdiği (veya neden bugün seninle konuşmak için buraya geldiğim) hakkında ne düşünüyorsun, bana anlatır mısın?"

(Bir cevap vermesi için bekleyin.)

(Eğer çocuk suçlamada bulunursa, 10. sorudan devam edin.)

(Eğer çocuk olay hakkında detaylı bir cevap verirse, 10.1. sorudan devam edin.)

(Eğer çocuk herhangi bir suçlamada bulunmazsa ve siz daha önce herhangi bir yetkiliyle iletişime geçildiğine dair bilgi sahibi değilseniz, 4. veya 5. sorudan devam edin.)

(Eğer çocuk herhangi bir suçlamada bulunmazsa ve siz daha önce bir yetkiliyle iletişime geçildiğini biliyorsanız, 3. sorudan devam edin.)

3. "Bir doktorla (öğretmenle, sosyal çalışmacıyla veya herhangi bir uzmanla) konuştuğunu duydum. Ne hakkında konuştuğunuzu bana anlatır mısın?"

(Bir cevap vermesi için bekleyin.)

(Eğer çocuk suçlamada bulunursa, 10. sorudan devam edin.)

(Eğer çocuk olay hakkında detaylı bir cevap verirse, 10.1. sorudan devam edin.)

(Eğer çocuk herhangi bir suçlamada bulunmazsa ve belirgin, görülebilir bir iz yoksa, 5 . sorudan devam edin.)

(Görünür izler olduğu durumda, polis memuruna bu izlerin fotoğrafları gösterilir ya da izlerden bahsedilir veya görüşme tıbbi değerlendirmenin hemen sonrasında ya da hastanede yapilır.

4. “Kolunda (başında, ayağında, bacağında vb.) izler (yaralar, çürükler vb.) olduğunu görüyorum (duydum). Bana bunun hakkında herşeyi anlatır mısın?"

(Bir cevap vermesi için bekleyin.)

(Ĕ̆er çocuk suçlamada bulunursa, 10. sorudan devam edin.)

(Eğer çocuk olay hakkında detaylı bir cevap verirse, 10.1. sorudan devam edin.)

(Eğer çocuk herhangi bir suçlamada bulunmazsa, 5. sorudan devam edin.)

\section{5. "Seni rahatsız eden birileri var mı?"}

(Bir cevap vermesi için bekleyin.)

(Eğer çocuk onaylarsa veya suçlamada bulunursa, 10. sorudan devam edin.)

(Eğer çocuk olay hakkında detaylı bir cevap verirse, 10.1. sorudan devam edin.)

(Eğer çocuk onaylamazsa ve herhangi bir suçlamada bulunmazsa, 6. sorudan devam edin.) 
6. (iddia edilen olayın gerçekleştiği yer ve zamanda) sana birşey oldu mu?"

(Not: Şüphelinin adından veya iddia edilen olaya ilişkin herhangi bir detaydan bahsetmeyin.)

(Bir cevap vermesi için bekleyin.)

(Ĕ̆er çocuk olay hakkında detaylı bir cevap verirse, 10.1. sorudan devam edin.)

(Eğer çocuk onaylarsa veya suçlamada bulunursa, 10. sorudan devam edin.)

(Eğer çocuk onaylamazsa ve herhangi bir suçlamada bulunmazsa, 7. sorudan devam edin.)

\section{7. "Biri sana doğru olduğunu düşünmediğin birşey yaptı mı?"}

(Bir cevap vermesi için bekleyin.)

(Eğer çocuk onaylarsa veya suçlamada bulunursa, 10. sorudan devam edin.)

(Ĕger çocuk olay hakkında detaylı bir cevap verirse, 10.1. sorudan devam edin.)

(Eğer çocuk onaylamazsa ve herhangi bir suçlamada bulunmazsa, 8. sorudan devam edin.)

Bekleyin.

\section{"Devam etmek içi hazır mısın? Devam etmeden önce bir ara verirsek daha iyi olur mu?"}

Devam etmeye karar vermeden önce, 8. ve 9. soruların görüşme öncesinde elde etmiş olduğunuz bilgiler doğrultusunda düzenlemiş olmalısınız. Bu soruların çocuğu yönlendirici olmadığından emin olmalısınız. Eğer soruları düzenlemediyseniz, görüşmeye devam etmeden önce soruları dikkatlice düzenleyebilmek için ara vermek iyi olacaktır.

8. "Biri sana (şüphelinin ya da failin adını vermeden, fazla detaya girmeden basitçe olayı özetleyiniz) yaptı mı?" (Örneğin, "Biri sana vurdu mu?" veya "Biri penisine (vücudunun özel bölgesine) dokundu mu?")

(Bir cevap vermesi için bekleyin.)

(Eğer çocuk onaylarsa veya suçlamada bulunursa, 10. sorudan devam edin.)

(Eğer çocuk olay hakkında detaylı bir cevap verirse, 10a. sorudan devam edin.)

(Eğer çocuk onaylamazsa ve herhangi bir suçlamada bulunmazsa, 9. sorudan devam edin.)

9. “Öğretmenin (doktor, psikolog, komşu vb.) ("senin diğer çocukların penisine dokunduğunu", "cinsel organ resmi çizdiğini”) gösterdi/anlattı. Sana birşey olup olmadığını öğrenmek istiyorum. Biri sana ................. (şüphelinin ya da failin adını vermeden, fazla detaya girmeden basitçe olayı özetleyiniz) yaptı mı?" (Örneğin, “Biri sana vurdu mu?" veya "Biri penisine (vücudunun özel bölgesine) dokundu mu?")

(Bir cevap vermesi için bekleyin.)

(Eğer çocuk onaylarsa veya suçlamada bulunursa, 10. sorudan devam edin.)

(Eğer çocuk olay hakkında detaylı bir cevap verirse, 10a. sorudan devam edin.)

(Eğer çocuk onaylamazsa ve herhangi bir suçlamada bulunmazsa, XI. bölümden devam edin.)

Olayların Araştırılması

10. (Eğer çocuk 6 yaşından küçükse, çocuğun ifade etmediği isim veya detayları kullanmadan çocuğun kendi sözleriyle iddia edilen olayı tekrarlayın.) 
(Sonra şöyle söyleyin:)

\section{"Bununla ilgili hatırladığın herşeyi bana anlat."}

(Bir cevap vermesi için bekleyin.)

(Eğer çocuk 6 yaşından büyükse, şöyle söyleyin:)

\section{"Bununla ilgili herşeyi bana anlat."}

(Bir cevap vermesi için bekleyin.)

\section{1. "Sonra ne oldu?" veya "Daha fazla anlatır misın?"}

(Bir cevap vermesi için bekleyin.)

(Bu soruyu olaya ilişkin tam bir açıklama alıncaya kadar ihtiyaç duydukça kullanın.)

(Not: Eğer çocuğun açıklaması genel bir tanımlama olursa 12. soruya geçin. Ancak, çocuk spesifik bir olaydan bahsederse, 10.2. sorudan devam edin.)

10.2. “O gece (ya da günü) tekrar düşün ve (çocuğun bahsettiği bir an)dan (çocuk tarafından belirtilen istismar olayı/iddia edilen olay)a kadar geçen sürede olan herşeyi bana anlat."

(Bir cevap vermesi için bekleyin.)

(Not: Bu soruyu olayın bütün bölümlerinin ayrıntılandırıldı̆̆ından emin oluncaya kadar sık kullanin.)

10.3. "(Çocuk tarafından bahsedilen kişi, olay, nesne vb.) hakkında daha fazla anlatır misin?"

(Bir cevap vermesi için bekleyin.)

(Not: Bu soruyu bu bölüm boyunca ihtiyaç duydukça kullanın.)

10.4. “Söz ettiğin (çocuk tarafından bahsedilen kişi, olay, nesne vb.) hakkında hatırladığın herşeyi bana anlat."

(Bir cevap vermesi için bekleyin.)

(Not: Bu soruyu bu bölüm boyunca ihtiyaç duydukça kullanın.)

(Belirtilen detaylar (örneğin olay dizisindeki sıralama gibi) konusunda kafanız karışırsa, şöyle söylemek yardımcı olabilir:)

“Bana çok şey anlattın ve anlattıkların gerçekten yardımcı oldu, ama biraz kafam karıştı. Anladığımdan emin olmak için lütfen baştan başlayalım ve bana (nasıl başladığını, tam olarak ne olduğunu ve nasıl sona erdiğini) anlat."

\section{Çocuk Tarafından Verilen Bilgilere İlişkin Odak Soruların Kullanılması}

(Açık uçlu sorular kullanılarak yapılan görüşme sonrasında, eğer hala iddia edilen olaya (suça) ilişkin önemli bazı ayrıntılar eksikse ya da net değilse, doğrudan soru tipini kullanın. Uygun olduğu anlarda açık noktaları doğrudan sorularla eşleştirmek önemlidir.)

(Not: Önce çocuğun söz ettiği detaya odaklanın ve sonra doğrudan soruyu sorun.)

\section{Doğrudan Soruların Genel Formatı Şu Şekildedir:}


11.“(Kişi, nesne, olay vb.)dan söz ettin, (doğrudan sorunun tamamlanması.)”

Örneğin;

a. "Dükkanda olduğunuzdan söz ettin. Tam olarak neredeydiniz? (Cevap vermesi için bekleyin.) Dükkan hakkında bana bilgi verir misin?"

b. "Daha önce annenin sana "uzun bir şeyle vurduğundan" bahsettin. O şey hakkında daha bana bilgi verir misin?"

c. "Bir komşunuzdan bahsettin. Onun adını biliyor musun? (Cevap vermesi için bekleyin.) O komşuyu bana anlatır mısın?" (Bir açılama istemeyin.)

d. "Sınıf arkadaşlarından birinin olayı gördüğünden bahsettin. Onun adı neydi? (Cevap vermesi için bekleyin.) Onun orada ne yaptığını bana anlatır mısın?"

\section{Olayların Ayrıştırılması}

12. "Bu olay bir kez mi yoksa birden fazla kez mi yaşandı?"

(Eğer olay bir kez yaşanmışsa, “Ara” bölümden devam edin.)

(Ĕ̆er olay birden fazla kez yaşanmışsa, 13. sorudan devam edin. Burada belirtilen olayların detaylarını araştırmayı unutmayın.)

Açık Uçlu Sorular Kullanarak Olayın Ayrıntılarının Belirlenmesi

13.“Son defada (ilk kez/ (şu) yerdeyken/ (iyi hatırladığınız farklı bir zaman ya da spesifik bir ana ilişkin)) olan herşeyi bana anlat."

(Bir cevap vermesi için bekleyin.)

13.1. “Sonra ne oldu?" veya "Daha fazla anlatır misın?"

(Bir cevap vermesi için bekleyin.)

(Not: Bu soruyu bu bölüm boyunca ihtiyaç duydukça sık kullanın.)

13.2. “O gece (ya da günü) tekrar düşün ve (çocuğun bahsettiği bir an)dan (çocuk tarafından belirtilen istismar olayı/iddia edilen olay)a kadar geçen sürede olan herşeyi bana anlat."

(Bir cevap vermesi için bekleyin.)

(Not: Bu soruyu olayın bütün bölümlerinin ayrıntılandırıldığından emin oluncaya kadar sık kullanin.)

13.3. “(Çocuk tarafından bahsedilen kişi, olay, nesne vb.) hakkında daha fazla anlatır misin?"

(Bir cevap vermesi için bekleyin.)

(Not: Bu soruyu bu bölüm boyunca ihtiyaç duydukça kullanın.)

13.4. "Söz ettiğin (çocuk tarafından bahsedilen kişi, olay, nesne vb.) hakkında bana herşeyi anlat."

(Bir cevap vermesi için bekleyin.)

(Not: Bu soruyu bu bölüm boyunca ihtiyaç duydukça kullanın.) 


\section{Çocuk Tarafından Verilen Bilgilere İlişkin Odak Soruların Kullanılması}

(Açık uçlu sorular kullanılarak yapılan görüşme sonrasında, eğer hala iddia edilen olaya ilişkin önemli bazı ayrıntılar eksikse ya da net değilse, doğrudan soruları kullanın. Uygun olduğu anlarda açık noktaları doğrudan sorularla eşleştirmek önemlidir.)

(Not: Önce çocuğun söz ettiği detaya odaklanın ve sonra doğrudan soruyu sorun.)

\section{Doğrudan Soruların Genel Formatı Şu Şekildedir:}

14.“(Kişi, nesne, olay vb.)dan söz ettin, (nasıl/ne zaman/nerede/kim/hangi/ne sorularıla) (doğrudan sorunun tamamlanması.)"

\section{Örneğin;}

a. "O an televizyon izlediğinden bahsettin. Tam olarak neredeydin?"

(Bir cevap vermesi için bekleyin.) "O anla ilgili herşeyi anlat bana."

b. “Daha önce babanın seni dövdüğünden bahsettin. Tam olarak ne olduğunu anlat bana."

c. "Bir arkadaşının orada olduğundan bahsettin. Onun adı neydi?"

(Bir cevap vermesi için bekleyin.) "Onunla ilgili herşeyi anlat bana."

d. "Daha önce amcanın seni öptüğünden (dokunduğundan, cinsel ilişkiye girdiğinden vb.) bahsettin. Tam olarak ne olduğunu anlat bana."

(Çocuğun bahsettiği olaya ilişkin ayrıntıları elde edebilmek adına bu bölümü tamamıyla tekrar edin. Eğer çocuk ikiden fazla olaydan bahsederse, önce "son olay" sonra "ilk olay" ve daha sonra "net hatırladığı diğer zaman" hakkında sorular sorun.")

\section{Ara}

(Çocuğa şöyle söyleyin:)

“Anlattığın herşeyi anladığımdan emin olmak istiyorum ve sormam gereken başka bir şey var mı bakmam lazım. Bana neler anlattığın üzerine düşüneceğim (aldığım notlarımı kontrol edeceğim/gidip kontrol edeceğim vb.)"

(Ara sırasında, elde ettiğiniz bilgilerin üzerinden geçin, Adli Görüşme Kontrol Listesini doldurun, eksik bilgi var mı kontrol edin ve görüşmenin geri kalan kısmını planlayın. Odak soruların yapılandırıldığından emin oldun.)

\section{Aradan Sonra}

(Çocuğun bahsetmediği ama önemli olduğunu düşündüğünüz bilgileri alabilmek için yukarıda örnekleri verilen doğrudan ve açık uçlu soruların birlikte kullanıldığı sorular sorun. Doğrudan sorunun ardından açık uçlu soru ("Bana daha fazla bilgi ver" şeklinde) kullanın. Bu soruları bitirdikten sonra VII. bölümünden devam edin.)

\section{Çocuğun Bahsetmediği Bilgilerin Açıklığa Kavuşturulması}

(Buraya kadar olan yaklaşımları denemenize rağmen adli süreç için önemli olduğuna inandığınız bazı bilgilerin hala eksik olduğunu düşünüyorsanız bu odak soruları kullanın. Bu soruları mümkün oldukça "Bana hatırladığın her şeyi anlat." vb. açık uçlu sorularla birlikte kullanmanız çok önemli.) 
(Not: Söz konusu durum birden fazla olayı içeriyorsa, olaylara ilişkin temel bilgileri alabilmek için çocuğun kendi sözlerini kullanarak odak sorularla çocuğu ilgili olaylara yönlendirin.)

(Bir sonraki olaya ait bilgileri almaya geçmeden önce her olay için bütün eksik bilgileri aldığınızdan emin olun.)

\section{Çocuğun Bahsetmediği Bilgileri Almak İçin Kullanılan Odak Soruların Genel Formatı}

"(Yer veya zamanı belli olan belirgin bir olaya ilişkin) hakkında olanları bana anlattığında, (kişi/nesne/durum vb.)den de söz ettin. Bu (odak soru) muydu?"

(Bir cevap vermesi için bekleyin ve uygun bir anda, şu şekilde devam edin: )

\section{"Bana hatırladığın her şeyi anlat."}

Örneğin;

a. "Bodrumda olduğunuz zaman onun kendi pantalonunu çıkardığından bahsetmiştin. Senin kıyafetlerine bir şey oldu mu?"

(Bir cevap vermesi için bekleyin ve çocuğun cevabından sonra şöyle söyleyin:)

"Bana hatırladığın her şeyi anlat."

(Bir cevap vermesi için bekleyin.)

b. "Son olan olay hakkında konuştuğumuzda, onun sana dokunduğundan bahsetmiştin. Kıyafetlerinin üzerinden mi dokundu?"

(Bir cevap vermesi için bekleyin ve çocuğun cevabından sonra şöyle söyleyin:)

"Bana hatırladığın her şeyi anlat."

(Bir cevap vermesi için bekleyin.)

c. "Kiyafetlerinin altından mı dokundu?"

(Bir cevap vermesi için bekleyin ve çocuğun cevabından sonra şöyle söyleyin:)

"Bana hatırladığın herşeyi anlat."

d. "Bana, oyun parkında olan bazı şeylerden bahsetmiştin. Birileri olanları gördü mü?"

(Bir cevap vermesi için bekleyin ve çocuğun cevabından sonra şöyle söyleyin:)

"Bana hatırladı̆̆ın herşeyi anlat."

e. “Diğer çocuklara benzer bir şey olup olmadığını biliyor musun?"

(Bir cevap vermesi için bekleyin ve çocuğun cevabından sonra şöyle söyleyin:)

"Bana hatırladığın herşeyi anlat."

f. "Ahırda olan bir şeyden bahsetmiştin. Bunun ne zaman olduğunu biliyor musun?"

(Bir cevap vermesi için bekleyin ve çocuğun cevabından sonra şöyle söyleyin:)

"Bana hatırladığın herşeyi anlat."

(Bir cevap vermesi için bekleyin.) 
Eğer Çocuk Ondan Almayı Beklediğiniz Bilgileri Vermekte Zorlanıyorsa

Sadece ilgili yönergeleri kullanın.

Söz konusu bilginin hangi konuşmalarda/görüşmelerde yer aldığını biliyorsanız, şöyle şöyleyin:

1. “(Şu zaman veya yerde) (şu kişiyle) konuştuğunu duydum. Ne konuştuğunuzu bana anlat."

(Eğer çocuk yeterli bilgi vermezse, 2. soruyu sorun; eğer çocuk daha fazla bilgi verebiliyorsa, şöyle söyleyin:)

"Bana hatırladığın herşeyi anlat."

(İhtiyaç duyarsanız "Bana bununla ilgili hatırladığın herşeyi anlat." vb. başka bir açı uçlu yönergeyle cevap almaya devam edin.)

Eğer daha önceki görüşmelere dair detayları biliyorsanız ve o bilgiler henüz size açıklanmamışsa, şöyle söyleyin:

2. “(Mümkünse suça ilişkin detayları belirtmeden iddiayı özetleyin) hakkında söylediklerini duydum. Konuyla ilgili hatırladığın herşeyi anlat bana."

(İhtiyaç duyarsanız "Bana bununla ilgili hatırladığın herşeyi anlat." vb. başka bir açık uçlu yönergeyle cevap almaya devam edin.)

3. Eğer bazı şeyler gözlenmişse, şöyle söyleyin:

a. "Birilerinin (olaya dair bir detay) gördüğünü duydum. Bana bununla ilgili hatırladığın herşeyi anlat."

(İhtiyaç duyarsanız "Bana bununla ilgili hatırladığın herşeyi anlat." vb. başka bir açık uçlu yönergeyle cevap almaya devam edin.)

Eğer çocuk inkar ederse, 3b. sorusundan devam edin.

b. “O (yer/zaman)da sana herhangi bir şey oldu mu? Bana bununla ilgili hatırladı̆ğın herşeyi anlat."

(İhtiyaç duyarsanız "Bana bununla ilgili her şeyi anlat." vb. başka bir açı uçlu yönergeyle cevap almaya devam edin.)

Eğer çocuğun vücunda yaralar ya da izler varsa, şöyle söyleyin:

4. “(Kolunda, bacağında vb.) izler (yara, çürük vb.) olduğunu görüyorum (ya da duydum). Bana bununla ilgili hatırladığın herşeyi anlat."

(İhtiyaç duyarsanız "Bana bununla ilgili hatırladığın herşeyi anlat." vb. başka bir açı uçlu yönergeyle cevap almaya devam edin.)

5. “Birileri sana (eğer çocuk hala bahsetmemişse şüphelinin/suçlununun adını ve suça ilişkin olayın detaylarını vermeden) yaptı mı?"

Eğer çocuk inkar ederse, bir sonraki bölümden devam edin.

Eğer çocuk bir şeylerin olduğunu kabul ederse, şöyle söyleyin:

"Bana bununla ilgili hatırladığın herşeyi anlat." 
(İhtiyaç duyarsanız "Bana bununla ilgili hatırladığın herşeyi anlat." vb. başka bir açık uçlu yönergeyle cevap almaya devam edin.)

\section{Açıklama Hakkında Bilgi}

"Benimle konuşmak için neden bugün buraya geldiğini anlattın. Bana birçok bilgi verdin ve olanları anlamam için bana gerçekten yardımcı oldun."

(Ĕger çocuk olaydan başka birine bahsettiğini belirtirse, 6.sorudan devam edin. Ĕ̆gr olaydan başka birine bahsetmemişse, mümkün olduğunca hızlı bir şekilde bilgi alabilmek için şöyle söyleyin:)

1. "(Son olay)dan sonra neler olduğunu anlat bana."

(Bir cevap vermesi için bekleyin.)

\section{2. "Peki sonra ne oldu?"}

(Not: Bu soruyu bu bölüm boyunca ihtiyaç duydukça kullanın.)

(Eğer çocuk bir beyanda bulunursa, 6. sorudan devam edin. Eğer yapmazsa, sıradaki sorudan devam edin.)

\section{3. "Neler olduğunu bilen başka biri var mı?"}

(Bir cevap vermesi için bekleyin. Eğer çocuk birinden (birilerinden) bahsederse, 6.sorudan devam edin.)

(Eğer çocuk bilen başka birinin olduğunu kabul ederse ancak bir isim vermezse, şöyle sorun:)

\section{"Kim?"}

(Bir cevap vermesi için bekleyin. Eğer çocuk birinden (birilerinden) bahsederse, 6.sorudan devam edin.)

4. "Diğer insanların (son olay) hakkında nasıl bilgi sahibi olduğunu öğrenmek istiyorum."

(Bir cevap vermesi için bekleyin. Eğer çocuk birinden (birilerinden) bahsederse, 6.sorudan devam edin.)

(Eğer eksik bilgiler olduğunu düşünüyorsanız, sıradaki sorulardan devam edin.)

5. "Senin ve (failin/şüphelinin) yanı sıra (çocuğun kelimeleriyle iddia edilen istismar olayı) hakkında bilgi sahibi olan ilk kişi kimdi?"

(Bir cevap vermesi için bekleyin.)

6. "(Çocuğun ifade ettiği "ilk kişi")nin olayla ilgili nasıl bilgi sahibi olduğu hakkında bildiğin herşeyi bana anlat."

(Bir cevap vermesi için bekleyin.)

(Sonra şöyle söyleyin:)

"Bununla ilgili daha fazla bilgi verebilir misin?"

(Bir cevap vermesi için bekleyin.)

(Eğer çocuk yapılan görüşme hakkında bilgi verirse, şöyle söyleyin:) 
Çocuklarla Yapılan Adli Görüşmeler İçin Ulusal Çocuk Sağlığı ve İnsan Gelişim Enstitüsü Protokolü (NICHD) Önerisi: Türkçe Versiyonu

“Konuştuklarınızla ilgili herşeyi bana anlat."

(Bir cevap vermesi için bekleyin.)

7. “(Çocuğun kelimeleriyle iddia edilen istismar olayı) hakkında bilgi sahibi olan başka biri(leri) var mı?"

(Bir cevap vermesi için bekleyin.)

(Sonra şöyle söyleyin:)

"Bununla ilgili daha fazla bilgi verebilir misin?"

(Bir cevap vermesi için bekleyin.)

(Eğer çocuk yapılan görüşme hakkında bilgi verirse, şöyle söyleyin:)

"Konuştuklarınızla ilgili hatırladı̆̆ın herşeyi bana anlat."

(Bir cevap vermesi için bekleyin.)

(Eğer çocuk başka birisine bilgi verdiğinden bahsetmezse, sıradaki bölümden devam edin.)

Kapanış

(Şöyle söyleyin:)

"Bugün bana birçok şey anlattın ve yardımın için sana teşekkür etmek istiyorum."

1. "Bilmem gerektiğini düşündüğün başka bir şey var mı?"

(Bir cevap vermesi için bekleyin.)

2. "Bana söylemek istediğin başka bir şey var mı?"

(Bir cevap vermesi için bekleyin.)

3. "Bana sormak istediğin soru var mı?"

(Bir cevap vermesi için bekleyin.)

4. "Eğer benimle tekrar konuşmak istersen, bu telefon numarasından beni arayabilirsin." (Adınızın soyadınızın ve telefon numaranızın yazılı olduğu bir kartı (kartviziti) çocuğa veriniz.)

\section{Tarafsız Bir Konu}

“Bugün buradan ayrıldıktan sonra ne yapacaksın?"

(Görüşmeyi sonlandırmadan önce çocukla birkaç dakika olaydan tarafsız bir konu başlığı üzerine konuşun.)

"Şu an (zamanı belirtin) ve görüşmemiz şimdi tamamlandı." 